\title{
A relação entre proporção da proximidade e tipos de encontros no espaço grupal
}

Laura Fernandes Vitucci ${ }^{1}$

\section{Resumo}

O presente artigo tem como objetivo investigar os tipos de encontros vivenciados no grupo terapêutico do "Projeto Psicose e Drogas", a partir da observação de modos-de-estar neste espaço social. Partindo da ideia de grupo como nó e das categorias de apreensão da Psicopatologia Fenômeno-Estrutural, principalmente espacialidade e temporalidade, faz uma breve descrição da "acontecência" do grupo apresentando os modos-de-estar e tipos de encontros observados neste espaço. Por fim, discute a proporção dos encontros como uma possível variável que faz do grupo um espaço de aproximação ou aniquilação.

Palavras-chave: Fenomenologia; Grupo Terapêutico; Espacialidade; Interpessoalidade.

\section{The relationship between the nearness proportion and kinds of encounters at the group space.}

\begin{abstract}
The present paper aims to examine the kinds of encounters deeply experienced at the therapeutic group from "Psychosis and Drugs Project", on the basis of observation of "ways - of - being" in this social space. Assuming the idea of a group as a knot, and from the perceiving classes of the Phenomenostructural Psychopathology, specially "spaceality" and temporality, it shows a brief description for the "happening" of the introduced group, the "ways-of-being" and kinds of encounters that has been observed in this space. Finally, this paper considers the proportion of the encounters as an attainable factor that turns the group into a space of forthcoming or annihilation.
\end{abstract}

Keywords: Phenomenology; Therapeutic group; "Spaceality”, Interpersonality.

\footnotetext{
${ }^{1}$ Psicóloga com Pós-graduação em Psicopatologia e Saúde Pública pela Faculdade de Saúde Pública da USP. Psicóloga do CAPS Infantil Itaim Paulista. Email: Ifvitucci@yahoo.com.br
} 


\section{Introdução}

A questão principal deste trabalho nasce de um incômodo frente ao trabalho grupal como única ou melhor possibilidade terapêutica para todo e qualquer público. Frente a esta ideologia, venho questionando o quanto esta prática abarca todas as demandas.

Atualmente, os serviços substitutos do modelo hospitalocêntrico, em especial os Centros de Atenção Psicossocial (CAPS), responsáveis pelo atendimento a pacientes com transtornos mentais graves, priorizam a atividade grupal (grupos terapêuticos, oficinas diversas e atividades externas e comunitárias), visando a inserção ou re-inserção social destes. Devolver o mundo aos pacientes psiquiátricos que antes ficavam reclusos, isolados e devolvê-los ao mundo que antes os excluía e escondia são as metas principais.

Diante disso, as atividades grupais são priorizadas como forma de integrá-los aos pequenos grupos, em espaços protegidos e acompanhados por equipes multidisciplinares, para depois inserí-los no mundo, nos grandes grupos, nos espaços públicos. Contudo, apesar da beleza dessa ideologia e da importância dessa integração paciente-mundo, permaneço com a minha dúvida sobre a generalização do trabalho grupal e o entendimento de que todos se beneficiariam deste tipo de encontro, sempre, sem exceções. Estar isolado e excluído pelo mundo é desumano e inadmissível. Porém, ser "integrado" a um mundo que machuca não seria violento da mesma forma? Se o propósito é deixar que os pacientes estejam-com, de forma saudável, terapêutica e inclusiva, será que podemos garantir que os grupos terapêuticos vêm exercendo estas funções?

Entendo que as atividades grupais são priorizadas também pela grande demanda destes equipamentos de saúde mental, que atendem extensos territórios e um número elevado de pessoas. Contudo, se a singularização e personalização dos tratamentos e projetos terapêuticos são essenciais nestes equipamentos, será que a inclusão maciça dos usuários em atividades grupais, sem olhar para suas limitações, não seria um erro?

Minhas experiências diversas com grupos, em serviços e áreas distintas, vêm ratificando essas inquietações. Nos grupos operativos que desenvolvia com adolescentes que cumpriam medida judicial de liberdade assistida, nos quais discutíamos temáticas como sexualidade, drogadição, cidadania e vida em comunidade, não percebia muitos benefícios para os participantes, que só compareciam porque estes grupos eram atividade obrigatória na medida judicial. 
Da mesma forma, nos grupos de orientação a familiares, as discussões eram cerceadas pelas questões legais que envolviam a medida. Não havia espaço para questões existenciais, troca de qualquer tipo, nem estabelecimento de vínculo entre os participantes. Não percebia aquilo como um grupo, mas sim um amontoado de pessoas. Não via nada de terapêutico naqueles encontros.

Recentemente, iniciei uma atividade em um Centro de Atenção Psicossocial Álcool e drogas na Zona Leste de São Paulo, onde, conforme supracitado, a atividade grupal é priorizada, em grupos terapêuticos ou oficinas.

Porém, a experiência que embasará a discussão aqui proposta se dá em um Projeto intitulado "Projeto Psicose e drogas" (PPD), no qual desenvolvi por 12 meses um grupo terapêutico com pacientes que apresentam este diagnóstico duplo. Este projeto acontece em um Centro de Tratamento e tem como objetivo esclarecer as relações entre a psicose e o uso de drogas, estabelecer os melhores tratamentos para esta condição dupla e investigar os meios para detecção precoce dos riscos e prevenção dos quadros psicóticos. O grupo é semanal e aberto, com duração de uma hora e meia, aproximadamente. Após o grupo, a equipe técnica efetua a discussão dos casos com base no método fenomenológico estrutural.

A escolha desta experiência dentre tantas se dá pela liberdade e autonomia que a estrutura do Projeto me propicia. Não há leis, portarias, normas, procedimentos nem ideologias que embasem ou perpassem minha prática. Dessa forma, tenho a possibilidade e o dever de refletir sobre a minha atuação e buscar melhorias que tornem o tratamento de cada paciente atendido, de fato, individualizado. Da mesma forma, como atendemos um número reduzido de pacientes (25) posso olhar para cada um de uma forma singular, percebendo e atuando sobre seus incômodos, angústias e limitações.

\section{Metodologia}

Apesar das minhas experiências e inquietações sobre grupos, meu objetivo neste trabalho é poder olhar para essa prática sem pré-conceitos, julgamentos e prévias opiniões. Para tanto, utilizarei o método fenomenológico como base e fundamentação para as minhas reflexões e discussões. Lançando mão da époché ou redução fenomenológica, olharei para os grupos terapêuticos do "Projeto Psicose e drogas", buscando uma compreensão das questões acima mencionadas. 
Segundo Tatossian (2006, p.25):

A fenomenologia se define, com efeito, por uma mudança de atitude que é o abandono da atitude natural e 'ingênua', quer dizer, uma certa atitude onde, psiquiatras ou não, apreendemos isto que encontramos como realidades objetivas, subsistindo independentemente de nós, quer sejam realidades psíquicas ou materiais. A fenomenologia não se interessa pelas realidades como tais, mas pelas suas condições de possibilidade e, portanto, não começa senão depois de ter, sob uma ou outra forma, praticado a redução fenomenológica que suspende a atitude natural e suas afirmações, ou melhor, suas teses implícitas ou explícitas de realidade.

Sendo assim, não partirei nem buscarei explicações, teorizações ou a elaboração de um manual sobre atividades grupais. Minha expectativa é uma investigação e a abertura de novas possibilidades de olhar para um fenômeno já tão discutido. Lembrando que:

Investigar é sempre colocar em andamento uma interrogação. É perguntar. Não se sai em busca da compreensão de um fenômeno tentando aplicar sobre ele uma resposta já sabida sobre ele mesmo. Investigar não é, assim, uma aplicação sobre o real do que já se sabe a seu respeito. Ao contrário, é a ele que perguntamos o que queremos saber dele mesmo. (Critelli, 2007, p.27)

E saber dele mesmo significa um saber inexato, impreciso, móvel e aberto. Então, o dizer deste trabalho sobre o grupo terapêutico será inexato por princípio, pois só pode ser assim. Nas palavras de Lima (2008):

um estatuto basilar e constitutivo da fenomenologia é a impossibilidade mesma da exatidão. Porque o mundo, para o fenomenólogo, é inapreensível e móvel e se projeta em um horizonte de abertura plena. (...) o fenomenólogo está, como todos nós humanos, condenado ao movimento. A diferença é que ele não se esquece jamais dessa verdade. (...) O conhecimento com que trabalhamos tem configuração aproximada, plástica, até mesmo transitória, assim como a água em nuvem que espraia e se dilui e se desfaz e não deixa de ser água. 


\title{
3. O grupo como nó
}

A fim de me desfazer da ideia de grupo como "amontoado de pessoas" e me distanciar de qualquer pré-conceito, busquei obras que falassem sobre o tema e justificassem a potência do trabalho grupal.

Em um livro que discute o "campo grupal", descobri que o vocábulo grupo tem origem no termo italiano groppo ou gruppo, que "aludia a um conjunto de pessoas esculpidas ou pintadas, passando por volta do século XVIII a significar uma reunião de pessoas, e rapidamente seu uso coloquial se espalhou" (Fernández, 2006, p.17).

Fernández (2006, p.17) discorre sobre o groppo scultorico, uma forma artística do Renascimento na qual:

\begin{abstract}
as esculturas que em tempos medievais estavam sempre integradas ao edifício passam a ser expressões artísticas em volume, separadas dos prédios, ao redor das quais é possível caminhar para apreciá-las, ou seja, é possível rodeá-las; muda assim a relação entre o homem, suas produções artísticas, o espaço e a transcendência. Ao mesmo tempo, outra das características do groppo scultorico a ser destacada é que suas figuras ganham mais sentido quando observadas como conjunto do que isoladamente.
\end{abstract}

O grupo poderia ser compreendido como um conjunto de pessoas que podem ser olhadas por diversas perspectivas e se relacionam com quem as olha; ganhando um novo sentido quando "agrupadas".

Outra ideia resgatada pela autora veio a acrescentar a essa formulação inicial sobre o grupo. Ela descreve que uma das primeiras acepções do termo italiano groppo era nó: “derivada do antigo provençal grop = nó, este por sua vez derivaria do germano Kruppa = massa arredondada, aludindo a sua forma circular" (Fernández, 2006, p.19)

Frente ao exposto, compreendi que grupo seria um conjunto de pessoas que podem ser olhadas por diversas perspectivas e se relacionam com quem as olha, ganhando um novo sentido quando "envolvidas neste nó". Um nó que as envolve e por elas é formado.

Porém, a imagem do nó me pareceu ambígua, pois representava tanto a união e proximidade extrema entre lados opostos como o sufocamento causado por isso. União e sufocamento inseparáveis. 
Essa ideia foi ratificada por algumas experiências no grupo terapêutico do projeto "Psicose e drogas", que serão discutidas a seguir.

\section{A "acontecência" do grupo}

Quando fui convidada a assumir o grupo terapêutico do "Projeto Psicose e Drogas", após o desligamento da equipe que o acompanhava há um ano, muitas questões surgiram: como um grupo pode ser efetivo junto a pacientes com este diagnóstico duplo (psicose e dependência química)? Como pensar atividades que atraiam a atenção destas pessoas e possibilitem alguma reflexão? Como entrar em um grupo que já existe, com participantes que já se conhecem, sem saber nada sobre eles e ainda assim dar continuidade ao que antes acontecia?

Decidi fazer a única coisa que podia: iniciá-lo e ver o que acontecia. Ir respondendo a estas questões enquanto o grupo ia acontecendo. Ir formando uma ideia sobre grupos e sobre este grupo específico a partir da minha caminhada junto a ele. Deixar que esta ideia surgisse como:

um cadáver da experiência. Ou melhor, uma idéia é uma espécie de lixo ou de secreção de um trajeto ou de uma andança. Estamos indo, somos um foguete ou uma hera se alastrando sobre um muro branco; então, alguém chega para conversar, pergunta por onde andamos e o que brotou nessa andança e dessa andança. É nesse sentido que lhe contamos uma idéia: algo recolhido e testemunhado num trânsito. (Pessanha, 2009, p.21)

Transitei neste grupo por doze meses e, no presente trabalho, apresentarei algumas ideia recolhidas nessa andança. Ideias, impressões, inquietações, angústias, afetos e frustrações que me atravessaram durante esse percurso.

Em alguns grupos, saí com a sensação de "dever cumprido", como se a atividade tivesse alcançado seus objetivos e atingido, de alguma forma, cada participante do grupo. Contudo, na maioria, saía com um sentimento de frustração, uma insatisfação com os "resultados", não que pretendesse ou pudesse mensurá-los. Porém, havia uma dúvida sobre a eficiência da atividade desenvolvida naquele grupo e os benefícios para cada participante. 
Essas sensações, muitas vezes, se dissipavam no momento da discussão de caso com a equipe médica, quando os acontecimentos, silêncios, incômodos e faltas do grupo iam ganhando nome, contorno e formato. Porém, em alguns encontros, a angústia permanecia demandando uma reflexão posterior, solitária, que ocorria no momento da escrita, quando o "acontecido" e o "sentido" transformavam-se em palavras, ganhando assim, algum sentido.

Neste caminho, formado pelas vivências do grupo, leituras e discussões de caso, fui compreendendo que esses afetos, que em mim brotavam, eram a "preservação da melodia da mente alheia no interior da mente do pesquisador" (Messas, 2010, p.11). Ou seja, eram os conteúdos dos participantes do grupo ressoando em mim e, somente "pelo exame das ressonâncias do patrimônio das vivências do paciente nas suas próprias vivências" (Messas, 2010, p.10) o pesquisador pode vislumbrar qualquer conhecimento científico.

Dessa forma, para falar da "acontecência" do grupo, teria que olhar para mim. Para compreender este nó, teria que antes aceitar que também estava unida e sufocada por ele. Porém, este "sufocamento" não poderia contaminar meu olhar sobre o grupo, nem impedir que a compreensão se desse a partir do real, sem a prioris.

Para tanto, utilizarei as categorias de apreensão da Psicopatologia Fenômeno-Estrutural como as lentes através das quais olharei para essa "acontecência" do grupo, como se fossem "boias que orientam o náufrago no escuro" (Messas, 2011)2.

\section{Temporalidade, espacialidade e interpessoalidade no (do) grupo}

"só quando esquecemos todos os nossos
conhecimentos é que começamos a saber" (Lispector, 1998)

As categorias de apreensão da Psicopatologia Fenômeno-Estrutural, a saber, interpessoalidade, espacialidade e temporalidade serão utilizadas para iluminar o real do que os participantes trazem e reproduzir na minha mente uma visão do que isso significa. Dessa forma, a presente discussão não resultará em interpretações e teorizações acerca do grupo ou de seus participantes, mas

\footnotetext{
${ }^{2}$ Comunicação oral na disciplina "Psicopatologia Fenômeno-Estrutural" ministrada no Curso de Especialização em Psicopatologia e Saúde Pública da Faculdade de Saúde Pública da Universidade de São Paulo, em 2011.
} 
sim em uma explanação e partilha de inquietações e impressões que foram ressoando em mim ao longo desta andança junto ao grupo.

\section{A. A interpessoalidade do (no) grupo}

A interpessoalidade é a categoria que possibilita o movimento psíquico, pois "situa-se nas fontes originárias dele, atuando como um catalisador continuado e vigoroso" (Messas, 2004, p.155). Segundo Messas (2010, p.156):

a melhor metáfora para o papel da interpessoalidade no dinamismo do movimento psíquico seja a da incubadora. Oferece as melhores condições para que o desenvolvimento de um novo ser se faça, na ausência de condições normais, sem modificar suas características essenciais. A interpessoalidade pela via da interconsciência- dilata o espaço necessário para que um conteúdo possa atingir plenamente sua maturação, diminuindo suas fragmentações e distorções.

Esta categoria diz respeito à inserção do ser no mundo, constituinte do ser humano, que possibilita o seu vibrar com o mundo e com os outros e é a matriz de qualquer terapêutica, inclusive grupal. Porém, no grupo terapêutico em questão, percebi que alguns participantes pareciam ter um eu muito poroso, exposto aos conteúdos do mundo, sem com ele conseguir vibrar. Como se os conteúdos dos outros participantes os invadissem e, por essa razão, o contato com eles tornava-se insuportável.

\section{B. A temporalidade do (no) grupo}

"A nota do presente dá sentido àquelas que foram tocadas no passado"

$\left(\right.$ Messas, 2011) ${ }^{3}$

Sobre a categoria da temporalidade, Messas (2004, p.87) explica que ela:

determina a abertura simultânea da consciência e de seus conteúdos às três dimensões, de passado, presente e futuro. A

\footnotetext{
${ }^{3}$ Comunicação oral na disciplina "Psicopatologia Fenômeno-Estrutural" ministrada no Curso de Especialização em Psicopatologia e Saúde Pública da Faculdade de Saúde Pública da Universidade de São Paulo, em 2011.
} 
combinação geométrica destas três dimensões faculta à consciência a experiência de fluxo, de uma corrente que a atravessa, partindo do passado, atingindo sua coloração máxima no presente e dirigindo-se inexoravelmente a um horizonte sempre inatingível, o futuro."

Esta categoria trata do fluxo temporal da consciência, situando a existência humana nos três tempos possíveis (passado, presente e futuro). Santo Agostinho (2000, p. 328) esclarece como a consciência se estofa num presente incontornável a partir da "lembrança das coisas passadas, visão presente das coisas presentes e esperança das coisas futuras".

Dessa forma, o passado é visto como algo atualizado, re-significado no presente; não mais como um tempo fechado (encerrado), causador de traumas que se manifestam no tempo presente. Segundo Messas (2010, p. 9):

não apenas aquilo que o presente fornece vale mais em termos de captação do ser do que o registrado como passado, mas também o material do passado recebe seu selo de validade única e exclusivamente a partir do seu enraizamento no presente. O passado é um subproduto do presente, sem autonomia ontológica.

Para Van den Berg (2000, p.72), "o passado é: o que era, como parece agora". Diante disso, passado e futuro aparecem "enodados" no tempo presente do grupo. O passado atualizado pelas vivencias atuais dos participantes: as vivências da psicose, o tratamento para dependência, várias internações. $\mathrm{O}$ futuro, algumas vezes, aniquilado por estas experiências, que afetam e até eliminam seus projetos existenciais.

Esta categoria parecia essencial para o trabalho com o grupo, já que tínhamos como objetivo conhecer e compreender as histórias daquelas pessoas marcadas pelo diagnóstico duplo - psicose e dependência \uso ou abuso de drogas.

Imaginava que o espaço do grupo propiciaria que as biografias dos participantes surgissem, deixando que o passado fosse des-coberto e atualizado pelas vivências atuais. A temporalidade de cada biografia surgiria através de suas narrativas. A dinâmica grupal, que envolve trocas e identificações, ampliaria este acesso à biografia e propiciaria uma compreensão mais ampla sobre o início do uso de drogas e da vivência psicótica.

Porém, ao longo dos encontros deste grupo, fui percebendo que o acesso às histórias de vida daqueles participantes não seria tão simples e imediato. 
Falar de si, do passado, de relações não parecia confortável àqueles pacientes. A minha busca por suas biografias teria que respeitar suas limitações.

Sabendo que deste grupo participam pacientes com diagnósticos distintos e nem sempre fechados, muitas possibilidades e entraves poderiam surgir. Além da vivência de uso ou abuso de drogas (de diversos tipos), todos têm em comum algum tipo de psicose, em algum momento da vida, que se manifesta de forma singular e marca o modo como cada participante consegue estar no grupo. Além disso, como o fluxo normal da consciência se encontra interrompido, esta recusa ao passado e "apego" ao presente poderiam ser compreendidos como parte disso.

Este fato foi ratificado durante a atividade do "Álbum de memórias", que foi escolhida, justamente, para despertar lembranças do passado, que pudessem ser narradas e discutidas no grupo. Propondo uma atividade concreta, utilizando fotos, desenhos, questões e até um jogo psicodramático, pretendia-se criar espaço para isso. Porém, a dificuldade permaneceu e muitos participantes não conseguiram se aproximar do próprio passado. Quando o faziam, relatavam um sentimento ruim e angústia diante das histórias recordadas.

Compreendo que a dor de recordá-las não esteja relacionada aos fatos em si, aos fatos acontecidos e "armazenados" em suas memórias, mas sim à atualização desses fatos que a vivencia atual impõe. Ou seja, as histórias da infância e adolescência, que poderiam ser lembradas com alegria ou nostalgia em outros momentos de suas vidas, nas psicoses, são recordadas com sofrimento. O sofrimento da psicose atual "contamina" as lembranças do passado.

Outras possibilidades podem ser observadas no grupo, como o "tempo da urgência" de alguns psicóticos, no qual "a expressão psicológica da urgência manifesta-se no constante e tenso estar à mercê dos outros, pela irritação contra eles e pelo sofrimento diante deles, ou seja, pela falta de indiferença." (Binswanger, 2009, p. 86).

Já a temporalidade dos melancólicos, na qual a sensação do fluxo do tempo não é mais pertencente ao indivíduo, que observa seu desenrolar sem poder participar do mesmo, era vivenciado por RE e G, que, grudados no passado (suas culpas e arrependimentos) não conseguiam projetar-se rumo ao futuro. Segundo Messas $(2011)^{4}$, “o futuro não pode ser mais experimentado como uma possibilidade por vir, o presente vivido através do passado liquida a

\footnotetext{
${ }^{4}$ Comunicação oral na disciplina "Psicopatologia Fenômeno-Estrutural" ministrada no Curso de Especialização em Psicopatologia e Saúde Pública da Faculdade de Saúde Pública da Universidade de São Paulo, em 2011.
} 
possibilidade de futuro. Sua vida está determinada na imobilidade do passado". O mundo torna-se sem sentido e apático aos olhos do depressivo. $\mathrm{O}$ presente é invadido por passado já acontecido, sem possibilidades de mudanças.

Frente ao exposto, não percebo uma temporalidade única no grupo terapêutico do projeto "Psicose e drogas". Sendo este composto por tantas singularidades e perpassado por psicoses diversas, não é possível determinar a temporalidade que nele prevalece. É um grupo no presente, formado por pessoas que vivenciam presentes diferentes (do passado ou do futuro).

\section{A espacialidade do (no) grupo}

A categoria da espacialidade permite:

a determinação de fronteiras de um eu, núcleo a partir do qual este, por assim dizer, troca informações com as diversas modalidades do não-eu, ou do ambiente. Ambiente composto seja pelas influencias da cultura, num extremo, até a presença vivenciada do corpo biológico, no outro extremo. A fronteira do eu espacializado determina, assim, a vivencia de intimidade com a realidade, daquilo que nos pertence como identidade e patrimônio básico e daquilo que nos atinge como exterioridade, como algo distinto de nós mesmos. (Messas, 2004, p. 87)

Tendo em vista que o grupo terapêutico é um espaço de intimidade, no qual cada participante (eu) fica em contato com o não-eu, a categoria da espacialidade se mostra essencial para a discussão deste trabalho. Para tanto, utilizarei algumas ideias de dois autores que discutem essa categoria.

Minkowski (1973), na obra intitulada "El tempo vivido", trabalha com as ideias de espaço claro e espaço escuro, para a compreensão da espacialidade vivida. Segundo ele, o espaço claro é espaço de evidências, onde os objetos aparecem e são confirmados pela coletividade. Nele aparecem os valores do coletivo, já que é um espaço de domínio público, socializado. Nesse espaço, podemos ver as coisas do mundo, mantendo uma distância entre nós e elas.

Essa distância que ele nomeia de distância vivida, é um espaço livre, no qual cada um pode expandir-se. Porém, em algumas vivências e patologias, essa distância diminui ou inexiste, causando uma proximidade excessiva e, muitas vezes, insuportável, das coisas e pessoas. Um exemplo disso, seria a vivência de um paciente esquizofrênico atendido no Projeto (B.). Ele relata que seus pensamentos negativos podem ser ouvidos pelos outros, que podem tentar 
agredi-lo por causa disso. Da mesma forma, acredita que seu olhar pode incomodar, agredir a todos, principalmente, quando está em algum transporte público ou no grupo terapêutico. Por essa razão, fica de cabeça baixa. O mundo está tão próximo, quase dentro, que ele não o suporta. Não há distância entre ele e os outros, que chegam a invadir sua mente e ouvir seus pensamentos.

Essa vivência diz sobre o espaço escuro, que é um espaço de excessiva intimidade, onde os objetos aparecem sem contorno e nitidez. Binswanger (2009, p. 108) no caso clínico intitulado "O caso Jürg Zünd", trata da "mundanização do si-mesmo, ou seja, da retirada progressiva de sua liberdade e de sua dominação pela necessidade (mundana) ou pelos acontecimentos (mundanos)". Segundo ele, isso ocorre em algumas psicoses porque o mundo compartilhado (mundo das relações onde existe o outro) engole o mundo próprio. Eles ficam à mercê do mundo:

O mundo torna-se então o poder que consome as suas forças e de tal forma que eles se mundanizam mais e mais, ou seja, de pessoas independentes, amorosas e livres eles se transformam em criaturas amarradas ao mundo, que vivem do precisar se comparar, não-livres, castigadas pelo medo, tornam-se um joguete de um esboço de mundo - do mundo como perigo. (Binswanger, 2009, p.123)

\section{Modos-de-estar no grupo}

Olhando a "acontecência" do grupo a partir dessas categorias, fui percebendo modos-de-estar que foram se destacando. Ou seja, enquanto olhava a relação de cada participante com o outro e com o tempo e espaço vividos, algumas características comuns entre eles foram saltando aos olhos e formando um desenho sobre modos-de-estar que ali co-existiam.

A opção de apresentar os participantes a partir de algumas similaridades não elimina ou compete com o que há de singular em cada um, pois mesmo lidando com o espaço de formas similares, dois participantes podem responder a este encontro (espaço-eu) de formas muito particulares. Porém, apresentar cada participante através da sua biografia, diagnóstico ou atuação no grupo levaria este estudo a "perder-se numa infinitude de exemplos individuais que, a despeito de refletirem a peculiaridade de cada existência tornariam inviável o estudo. Há que se reduzir o campo temático a ser investigado, sem perder a capacidade de visar o particular" (Messas, 2008, p.4). 
No artigo acima citado, Messas (2008, p.4) justifica a escolha pelos tipos ideais de Jaspers como "ferramentas eficientes para uma primeira aproximação de vidas individuais". Utilizando autores da Psicopatologia Fenomenológica como Binswanger e Blankenburg, o autor postula que há:

duas vantagens na escolha metodológica do tipo ideal. A primeira delas deriva do fato de serem os tipos apenas um ponto de iluminação para o início de um estudo. Assim sendo, permitem a identificação e descrição de caracteres individuais dos casos clínicos estudados que não estejam contemplados em sua definição; como conseqüência, não cegam o investigador para características não contidas na definição sempre abstrata de um tipo e não o prendem em uma camisa de força intelectual redutora e empobrecedora para as ambições da ciência. Essa peculiaridade também possibilita a substituição de um tipo ideal por outro, de acordo com as necessidades ditadas pelo andamento da pesquisa. Essa plasticidade torna a classificação por tipo ideal um gênero de taxonomia transitória que protege a psicopatologia contra o fenômeno de reificação, pelo qual se toma por real e definitivo aquilo que é meramente ideal e passageiro. A segunda vantagem é a possibilidade de escapar à nociva normatização do comportamento humano travestida de ciência baseada em evidências, já que os tipos ideais não se definem a partir de uma média considerada como uma normalidade abstrata a ser atingida, mas sempre por meio de uma relação recíproca entre si. Em outras palavras, um tipo define-se unicamente pela comparação com outro tipo, como variante das proporções antropológicas contidas em cada vivência. (Messas, 2008, p.5 )

Na busca por esta plasticidade, descreverei os participantes do grupo a partir de tipos ideais, que aqui nomearei de modos-de-estar, que foram surgindo e se destacando no espaço grupal. Como olharei apenas uma possibilidade das suas existências e não do todo, não falarei sobre o ser, mas o estar, como uma encarnação transitória de algo componente do ser, pois o primeiro independe do nó grupal e o segundo está inexoravelmente relacionado a ele.

Para tanto, compreendi que as categorias da espacialidade e da interpessoalidade são essenciais para olhar e compreender esta relação do ser com o grupo que traz implícitas as relações ser-espaço e ser-outro. Nomeei três modos-de-estar de acordo com a minha percepção e da forma como estes ressoavam em mim. São eles: os incomodados no contato; os abusadores de espaço e os neutros, que foram pensados e desenhados a partir da forma como cada pessoa participa, interage, atua e se manifesta no grupo. 


\section{A. Incomodados no contato}

Este tipo é formado pelos participantes que suscitaram grande parte das inquietações e questões levantadas neste trabalho. São aqueles que parecem incomodados, aniquilados, invadidos pelos demais; como se a fala, o olhar, a abordagem de outros os penetrasse com tanta violência, que ora os impedia de permanecer no grupo, ora os incomodava.

A paranoia, o medo, a desconfiança ou alguma experiência delirante impediam que se sentissem familiarizados com o grupo, todos os assustavam. O grupo (modo plural) parecia espaço de rigidez, onde uma "massa anônima" parecia invadi-los e ameaçá-los. Como se fosse uma multidão de desconhecidos que transformavam o contato possível naquele grupo em sufocamento. $\mathrm{O}$ nó que o grupo é parecia colocá-los no centro e, fortemente, apertá-los. A presença do outro era sentida quando se tornava incômoda, agressiva. O outro só existia como invasor. O nó só surgia quando alguém parecia enforcado, sufocado por ele.

O grupo parecia aumentar esta dor, pois exigia o encontro com outros e impossibilitava esconderem-se. Estariam ali expostos, em uma insuportável evidência. De espaço de proteção, o grupo passava a espaço de opressão. Esta impressão se confirmava na postura, no incômodo e nos relatos de alguns participantes.

Como exemplo deste tipo, B. um jovem de 23 anos, diagnosticado com esquizofrenia paranoide, fez uso de maconha durante 10 anos, frequenta o projeto há 1 ano e 3 meses. Há 5 meses, é atendido somente individualmente, pois descrevia e transparecia grande incômodo no grupo, principalmente, quando era abordado, questionado ou quando comentavam suas falas ou tentavam aconselhá-lo. Tamanho seu incômodo no contato com o outro e o mundo que verbalizou, em um atendimento individual, seu desejo de "ter uma capa igual a do Harry Potter para ser invisível".

R. 27 anos, fez uso de maconha e cocaína durante 10 anos, diagnosticado com esquizofrenia, com sintomas paranoicos, frequenta o projeto há 1 ano e é atendido somente individualmente há 10 meses. No grupo, permanecia agitado, levantando diversas vezes e respondendo às questões de forma objetiva e monossilábica. Seu incômodo ressoava em mim como um pedido de socorro, um grito por libertação, soltura e desencarceramento daquele espaço grupal.

H. 24 anos, faz uso de maconha há 3 anos, diagnosticado com esquizofrenia, frequenta o projeto há 3 meses. Durante os grupos, demonstra 
agitação corporal, bufando todo o tempo como se estivesse sempre entediado. Quando abordado, pensa demasiadamente em suas respostas e pouco fala.

$\mathrm{B}$, mencionado anteriormente, assim como $\mathrm{R}$ e outros participantes do grupo, parecem vivenciar uma proximidade tão grande dos outros que os incomoda e invade. Como se estivessem nus ou em carne-viva, sem nenhuma proteção e cada olhar, cada palavra ou a simples presença do outro os penetrasse com violência e machucasse.

A ideia de "mundanização do si mesmo", de Biswanger, parece explicitar essa invasão vivenciada por B e R, que parecem, muitas vezes, invadidos pelo outro, pelas suas falas, seus olhares, que ora julgam, ora perseguem, pela simples presença do outro. Por isso, a impressão é que vivem uma constante desconfiança, suspeita e medo e uma busca por abrigo, discrição, anonimato, esconderijo. Como não mais consegue "se assenhorar do mundo, mas torna-se seu vassalo, ele forçosamente deve se encontrar em um estado constante de angústia de catástrofe" (Binswanger , 2009, p. 83).

A espacialidade parece sempre coercitiva, rígida ou invasiva. Não há troca, somente pressão. Há uma fratura das membranas do eu, por isso apresentam uma porosidade excessiva. $\mathrm{O}$ mundo invade, persegue, subjuga. (Messas, 2011) No caso de R paranóico, todo espaço é eu, não há vazios. Vive como se estivesse à flor da pele. Ou se sente protegido ou em um filme de terror. O espaço do grupo parecia invadi-lo de tal forma, que não pôde mais suportá-lo. Por essa razão, passei a atendê-lo individualmente.

Otto Dörr (1995, p.44) descreve a vivência de um paciente que exemplifica a sensação desses incomodados:

Federico se muestra profundamente afectado por el otro en cuanto cuerpo y es incapaz de una exacta delimitación con respecto a los demás, llegando incluso a fundirse por momentos con aquél, perdiendo, tanto como el enfermo paranoide, la reciprocidade, el uno con respecto al otro (das Einander). Para él el otro tambiém se convierte en un mero acontecimiento... con toda su prepotencia. (Von baeyer)

\section{B. Abusadores de espaço}

Ao contrário do modo-de-estar anterior, neste caso a questão das drogas é prioridade nas falas dos participantes. Mesmo os que se encontram abstinentes há longos períodos, trazem a temática das drogas em quase todos os 
encontros, ora relembrando de forma vívida o período de uso, ora rejeitando as vivências desta fase.

Alguns participantes deste tipo frequentam e valorizam os grupos de NA ou AA, repetindo frases e conselhos ouvidos nestes locais e reproduzindo os ensinamentos dos 12 passos. Eles usam o grupo como lugar de desabafos, um espaço para seus discursos, como se o "quem escuta" não importasse, desde que houvesse "público" para ouvi-los. Muitas vezes, suas falas "esvaziadas" e "artificiais" pareciam mais próximas de palestras do que de narrativas ou depoimentos.

Três participantes exemplificam este tipo. E.P., 55 anos, usuário de crack há 15 anos, diagnosticado com psicose há 25 anos, abstinente há 2 meses, participa do PPD há 1 ano, não falta ao grupo e comparece ao projeto mesmo quando não participa do grupo. EP fala sobre a infância, o relacionamento tumultuado com a companheira e as enteadas e seu histórico com as drogas detalhadamente, repetindo os mesmos fatos frequentemente, exaltando suas conquistas e seus valores. Considera-se um craque que comandou e venceu o crack

R. 37 anos, iniciou uso de álcool com 7 anos de idade, usuário de cocaína há 10 anos, abstinente há 6 meses, diagnosticado com neurose obsessiva, participa do grupo há 4 meses. Frequenta grupos de NA e tornou-se secretário de um deles, além de apadrinhar outros participantes. No grupo terapêutico, descreve detalhes da sua vida íntima e repete o mesmo tema central da sua angústia em todos os grupos.

G. 40 anos, fez uso de crack e cocaína por 26 anos, abstinente há 2 anos, apresenta sintomas como fortes dores de cabeça e zumbidos no ouvido. Não falta aos grupos e relata suas vivências e angustias com detalhes, demonstrando grande sofrimento, contaminando o grupo com seus relatos.

Embora as falas destes participantes nem sempre pareçam reflexivas, percebo que este espaço de escuta e encontros se mostra fundamental no tratamento, bem como na construção de novas relações. Contudo, a forma de utilizar o espaço grupal muitas vezes parece excessiva, abusiva, como se pudessem ocupar todos os espaços e silêncios com suas demandas. Muitas vezes, suas falas repetitivas e longas parecem incomodar os demais e tornar a permanência no grupo insuportável para eles.

Porém, apesar de utilizarem o espaço do grupo para isso, não parecem compartilhar suas histórias, apenas despejá-las. Como se não houvesse um outro com quem dividir ou trocar experiências, mas sim depósitos para suas cargas. Dessa forma, entendo que os "incomodados no contato" sejam 
agredidos pelos excessos dos "abusadores de espaço". Ou seja, para existir um aniquilado, precisa haver um aniquilador. Para que os "incomodados" existam nesse espaço grupal, precisa haver alguém que os incomode. Percebo que o que é aproximação para alguns, torna-se aniquilação para outros.

\section{Neutros}

O terceiro modo-de-estar percebido no grupo terapêutico do "Projeto Psicose e Drogas" é o da neutralidade. São os participantes que não parecem afetar os demais, nem por eles serem afetados. Ou seja, não parecem incomodados ou invadidos pelos excessos dos abusadores, nem invadem os incomodados. Há uma neutralidade no contato que os protege do primeiro grupo e, ao mesmo tempo, os afasta do segundo.

Para alguns participantes diagnosticados com esquizofrenia, parece faltar uma porosidade, por isso o embotamento afetivo. $\mathrm{H}$ e L, por exemplo, não pareciam afetadas, muito menos invadidas por nenhum conteúdo "alheio". $\mathrm{O}$ sono de L. em alguns grupos, que ressoava em mim como tédio absoluto, ratifica essa impressão. $H$ atravessava as discussões com assuntos diversos, descontextualizados dos temas discutidos pelos demais.

Elas estavam no e com o grupo, mas pareciam alheias. Mesmo assim, frequentam o grupo com regularidade e suas mães confirmam a importância deste espaço para elas, o que parece demonstrar que o sentir menos não impede que eles estejam-com, apenas diminua o impacto deste encontro.

H. em um grupo disse que gostava de estar ali porque conseguia relaxar. $\mathrm{L}$ mencionou que se sentia bem com aquelas pessoas. Percebia que o espaço do grupo era o único no qual estas participantes podiam ser e estar sem serem rejeitadas ou discriminadas pelas suas falas, muitas vezes, incoerentes e desconexas. O espaço grupal tornara-se então um espaço de aceitação, respeito e compreensão; garantindo encontros menos violentos do que os que elas vivenciavam em outros locais.

\section{Espaço social de encontros}

Entendo como espaço social um local de estar-junto, con-vivendo, compartilhando, independentemente de condições socioeconômicas, classe social, nível cultural: 
De todas as possibilidades essenciais de espacialidade que indivíduos possam apresentar, o espaço social é o que mais se destaca pela clareza e objetividade. O espaço social é a ágora para a qual confluem as percepções de uma determinada sociedade em um determinado momento do fluxo histórico. (Messas, 2010, p. 18)

A ágora do Projeto "Psicose e drogas" é o grupo terapêutico, no qual os encontros acontecem e cada participante ocupa seu lugar neste espaço compartilhado, afetando e sendo afetado por ele. Segundo Chamond (2011, p.6):

Em fenomenologia, o espaço sempre é espaço tímico, ou seja, um espaço afetado por uma coloração afetiva fundamental. A tonalidade climática especifica uma forma de 'presença à...'; ou seja, um modo de comunicação determinado com as coisas, num mundo que não está simplesmente diante de nós, mas que atravessa o pathos inerente à situação.

Dessa forma, o espaço social do grupo afeta os participantes de formas diversas, proporcionando encontros com sentidos diferentes.

Muitas definições para a palavra encontro são possíveis na língua portuguesa: topar com; descobrir o que se procura; atinar com; defrontar-se com; deparar-se com; ligar-se, juntar-se, unir-se; chocar-se, colidir; esbarrar com; dar de frente; embater-se, chocar-se; bater-se em duelo; disputar; opor-se. A palavra é tão complexa que pode revelar sentidos opostos de acordo com a preposição que a acompanha: ir de encontro significa chocar-se, colidir; enquanto ir ao encontro significa aproximar-se.

Otto Dörr (1995, p.31) no seu livro "Psiquiatria Antropológica: contribuciones a uma psiquiatria de orientación fenomenológicoantropológica", cita dois autores para definir "a essência do fenômeno de encontro": "W.v. Baeyer (1955) ve el encuentro como un fenómeno interpersonal originario, fundamentado en la estructura óntico ontológica de la existencia (Dasein) como ser-con (Mitsein)". Ele segue:

Lain Entralgo distingue dos momentos constitutivos del encuentro: la percepción y la respuesta. La percepción del outro puede dejarme indiferente o afectarme. Em el primer caso el outro es para mi objeto de percepción em el marco de uma nostridad plural dada previamente ('el' y 'yo'), em cambio, em el caso de la percepción que afecta se produce uma nostridad dual (M. Scheler) que precede a la diferenciación entre um 'tú' y um 'yo'. Em ella descubro que mis possibilidades de vida son possibilidades compartidas. Al acto involuntário de la percepción lo sigue e lacto voluntario de la respuesta, la cual 
puede ser dada em forma impersonal o personal. Com mí respuesta impersonal yo destruyo el estado de nostridad dual que encierra um 'tú' facultativo y reduzco al outro a un 'él', es decir, el encuentro conduce a uma objetivación del outro. Sin embargo, com mi respuesta personal yo me muestro al outro, me expongo ante él y me comprometro com él. La respuesta personal implica responsabilidade ante el outro y ante mi mismo. Em este encuentro el outro se transforma em 'tú', yo me transformo em ' $\mathrm{yo}^{\prime}$ ', se forma um 'nosotros' que impulsa al intercambio. Em la apertura reciproca o tal vez em la fusión de los espacios existenciales próprios, el outro se convierte para mí y yo para él em persona o em prójimo. El mundo se transforma em nuestro mundo comum.

Diante disso, o grupo terapêutico seria um espaço de encontros, de "fusão dos espaços existenciais" e de "mundo comum". Porém, alguns participantes se sentem próximos, "pertencidos", acompanhados, enquanto outros podem se sentir em colisão ou aniquilados.

Descreverei a seguir os dois tipos de encontros possíveis no grupo terapêutico, vividos pelos modos-de-estar acima descritos, a fim de refletir sobre as diferenças entre eles.

\section{A. Grupo como espaço de aproximação}

Alguns participantes do grupo parecem vivenciar encontros essenciais no grupo. EP, por exemplo, refere que aprendeu a se relacionar com as pessoas neste grupo, se tornando mais "sociável e simpático". Ele refere que ali construiu "amizades saudáveis" e que pode conversar sobre "assuntos saudáveis"(sic). Ele interage com os demais, comentando, aconselhando ou simplesmente se identificando com as falas e histórias. Recebe os novos participantes de forma afetiva, descrevendo as vantagens de frequentar aquele espaço.

Os "abusadores", bem como os "neutros" usam o espaço grupal para estar-com de uma forma que não conseguiriam em outros espaços, ou porque seus excessos incomodariam ou porque o embotamento afetivo e a excentricidade do seu modo-de-ser seriam rejeitados. Dessa forma, o grupo terapêutico torna-se espaço de aproximação com o outro e de alargamento do seu espaço vivencial. 


\title{
B. Grupo como espaço de aniquilação
}

Algumas vezes, o excesso e vazio das falas dos "abusadores de espaço", bem como a explanação de detalhes íntimos, parecem chocar e incomodar outros participantes mais sensíveis. Nesses momentos, o grupo parece um espaço de aniquilação.

Para entender esta "aniquilação", busquei um autor que trata desta questão. Laing (1982) postula três formas de "aniquilação" que o ser teme vivenciar: a absorção, implosão e a petrificação.

Sobre a absorção, ele diz que o ser teme o relacionamento com qualquer pessoa ou coisa e até consigo mesmo, por causa da incerteza e da instabilidade da sua autonomia, deixando-o vulnerável ao temor de que estes outros possam absorver sua identidade:

ele se sente como um homem que se salva do afogamento somente pela mais estrênua, constante e desesperada atividade. A absorção é sentida como o risco de ser compreendido (e como tal envolvido, incluído), de ser amado, ou mesmo simplesmente ser visto. (Laing, 1982, p.47)

Segundo Laing (1982, p.47), a principal manobra utilizada para livrar-se do temor da absorção e, consequentemente, da perda da identidade é o isolamento:

\begin{abstract}
Em vez de polaridades de separação e relacionamento baseadas na autonomia individual, existe a antítese entre a completa perda do ser pela absorção na outra pessoa (engulfment) e a completa solidão (isolamento). Não existe uma terceira possibilidade segura de relacionamento dialético entre duas pessoas.
\end{abstract}

Nesse temor da absorção, o amor do outro e sua compreensão são ainda mais temidos que o seu ódio: "ser compreendido corretamente é ser absorvido, cerceado, devorado, mergulhado, comido, sufocado, abafado pelo que supõe seja a ampla compreensão de outra pessoa" (Laing, 1982, p.47).

Segundo Laing (1982, p.45) é natural que um indivíduo que vivencie esta perda de identidade não se sinta seguro no mundo e com-os-outros, pois as circunstâncias e relações comuns da vida diária representam uma ameaça constante à sua existência, "uma contínua e mortal ameaça".

Outra possibilidade da perda de identidade, segundo Laing, é a implosão. $\mathrm{O}$ indivíduo sente um vazio que é ele próprio e, embora anseie para 
que este vazio seja preenchido, teme a possibilidade de que isso aconteça porque acha que ele só pode ser "o medonho nada desse mesmo vácuo":

\begin{abstract}
Qualquer contato com a realidade é sentido em si mesmo como terrível ameaça, porque a realidade sentida naquela posição é necessariamente implosiva e assim, do mesmo modo que o relacionamento na absorção, em si mesma uma ameaça àquilo que a identidade do indivíduo supõe possuir. (Laing, 1982, p.49)
\end{abstract}

Por último, Laing postula a petrificação ou despersonalização como outra forma de "aniquilação". Essa vivência diz respeito a uma forma de terror de ser ou transformar-se em um objeto, uma coisa. A pessoa não reage aos sentimentos do outro e pode até considerar que o outro não os tenha: "sendo tratada como 'objeto', sente que sua subjetividade se esvai como sangue foge do rosto. (...) exige constante confirmação dos outros de que possui sua própria existência como pessoa". (Laing, 1982, p.50)

Para Laing, renunciar à própria autonomia é uma forma de salvaguardála:

Transformar-se em pedra torna-se um meio de não ser petrificado por outra pessoa. (...) ser duro como pedra é adiar o perigo de ser transformado em algo morto por outra pessoa. Compreender-se totalmente (absorver-se a si mesmo) é uma defesa contra o risco de ser atraído para o redemoinho que constitui o modo de ser visto por outra pessoa. Consumir-se no seu próprio amor impede a possibilidade de ser consumido por outrem. (Laing, 1982, p.55)

Compreendo que o grupo aconteça como um espaço de absorção e implosão para alguns participantes, que temem que a presença de outros diminua ou elimine seu próprio espaço, bem como seu si-mesmo. Sem fronteiras do eu, o outro os invade, absorve e implode. Para evitar isso, somente afastando-se do grupo, como no caso de R; ou mantendo-se alheio a ele, de cabeça baixa, como B. Isolar-se, afastar-se do grupo parece a única "salvação".

Percebo que, embora não consigam interagir com os demais participantes e nem mesmo suportem suas falas, isso não ocorre porque os incomodados estejam distantes ou sejam indiferentes aos outros, pelo contrário, é a exacerbada proximidade que os impede de estar-com, fazendo do contato uma colisão e do encontro uma aniquilação. 


\section{A proporção da proximidade e os tipos de encontros no espaço grupal}

Se a aproximação e aniquilação são dois pólos do fenômeno encontro, o que as diferencia afinal? Seria a qualidade do encontro ou a quantidade da aproximação? O nó que o grupo é pode apertar de formas distintas a cada modo-de-estar ali presente?

Para pensar essas questões, utilizarei as noções de direção de sentido e proporção antropológica propostas por Binswanger, explicitadas no artigo de Chamnond (2011, p.5): “a direção de sentido é uma estrutura unitária puxada, esticada, entre duas polaridades contrárias. (...) Cada termo só tem sentido no seio da dualidade que ele forma com seu contrário e que constituem as diástoles e sístoles da existência".

As polaridades do encontro, conforme supracitado, são a aproximação e a aniquilação, lados contrários que se complementam, pois não há aniquilação sem antes ter havido aproximação e toda aproximação pode levar a uma colisão. Dessa forma, as "diástoles e sístoles da existência" surgem nessa relação como o relaxamento da aproximação e a contração da aniquilação. A primeira alargando o espaço vivido e a segunda o comprimindo.

Mas, será possível um equilíbrio destas formas de encontro para que o grupo seja sempre um espaço de saúde? Segundo Chamond (2011, p.6):

O equilíbrio entre as direções de sentido constitui aquilo que Binswanger chama de a proporção antropológica. A proporção justa, por exemplo, entre o baixo e o alto, permite ao homem encontrar sua medida justa, de ser sua própria possibilidade na sua história e de encontrar sua forma pessoal de realização.

E este equilíbrio é necessário para que haja saúde:

A justa proporção antropológica se define pela proporção da verticalidade e da horizontalidade, pelo equilíbrio entre a ascensão e o caminhar, entre a vontade de crescer e de pegar altura e da experiência prática do alargamento da vida, ou ainda entre a visão mais alta e mais larga sobre o mundo. Dito de outra maneira, a saúde depende da justa proporção antropológica entre a aspiração para chegar ao alto e a compreensão do mundo (na horizontalidade). (...) Quando existem desproporções antropológicas entre as dimensões espaciais da presença, o ser homem não pode se realizar autenticamente." (Chamond, 2011, p. 6) 
Frente ao exposto, penso que a proporção dos encontros no grupo terapêutico seja a variável que os torne aproximação para uns e aniquilação para outros. Ou seja, tanto incomodados como abusadores e até os neutros vivenciam encontros no espaço grupal, porém, nos primeiros, o outro está tão próximo que colide ou invade seu ser; nos abusadores, o outro está somente ali e a aproximação é suficiente apenas para ouvi-los e nos neutros a aproximação não os afeta.

Enquanto os incomodados são penetrados pela presença do outro, os abusadores apenas a usam e os neutros pouco a sentem. A proporção da proximidade e, consequentemente, do encontro varia nesses três modos-deestar.

\section{O lugar do psicólogo neste nó}

Todas as inquietações e reflexões deste trabalho surgiram do meu enodamento no grupo terapêutico do PPD e das questões que foram ressoando em mim. Em meio a este nó, fui descobrindo e construindo o meu lugar neste espaço, seja como coordenadora, terapeuta ou acompanhante.

Fui percebendo que as necessidades de cada modo-de-estar eram diversas e, muitas vezes, contrárias. Enquanto os incomodados precisavam de proteção para que a violência dos demais não os ferisse; os abusadores precisavam que alguém delimitasse seu abuso.

Inicialmente, percebia que estas duas demandas eram distintas e exigiriam que minha atuação fosse duplicada. Contudo, após um ano acompanhando este grupo, entendo que as demandas são complementares e minha atuação única. Se os abusadores invadem os incomodados com seus excessos, comprimindo seus espaços vividos e aniquilando a sua existência, precisaria atuar como uma barreira entre eles, barreira esta que controlasse a enxurrada de conteúdos dos primeiros e impedisse que os outros se afogassem nela.

A coordenação do grupo se daria neste espaço intermediário, no espaço entre os dois modos-de-estar. Da mesma forma, o meu lugar de terapeuta se daria no momento em que os abusadores conseguissem estar-com sem ferir e os incomodados, estar-com sem ferir-se. Como se o estar-junto estivesse rasgado, esgarçado nos dois casos e o meu papel fosse auxiliar na costura, ponto por ponto. E, assim como um marinheiro aprende diversas formas de fazer um nó, a 
fim de salvar sua embarcação, fui e estou aprendendo diversas formas de usar o nó que o grupo é e forma, a fim de cuidar das existências ali presentes.

\title{
10. Conclusão
}

\author{
"Mesmo a mais afinada literatura \\ é mera mimese de uma realidade \\ vivida e inefável."
}

(Messas, 2010)

A partir das reflexões aqui apresentadas, muitas vivências do (no) grupo foram ganhando contorno e muitas inquietações, ganhando formato.

Pensar a finalidade e a efetividade do trabalho grupal a partir de um único grupo pode ser algo limitado, mas oferece pistas para refletir sobre a generalização do uso desta terapêutica para todo e qualquer público, sofrimentos psíquicos, angústias e modos-de-ser.

A partir do acompanhamento do grupo terapêutico do "Projeto Psicose e Drogas" e das reflexões suscitadas neste trabalho, percebo que o espaço grupal é um importante espaço de encontros. Entretanto, nem sempre estes encontros são terapêuticos ou ainda saudáveis. Nem todo encontrar-se é estar-com, algumas vezes pode ser estar-sob ou estar-sobre o outro, sendo aniquilado por ele ou aniquilando-o.

O espaço coletivo do grupo propicia alargamento do espaço vivencial para aqueles que vivenciam a aproximação proporcionalmente à sua condição existencial. Contudo, para aqueles nos quais a aproximação é excessiva, há o estreitamento do seu espaço e do seu próprio ser.

A opção dos atendimentos individuais para os "incomodados no contato" tem sido efetiva no que tange à diminuição da exposição e violência do contato humano. No contato dual (terapeuta-paciente) o eu-poroso destes se sente menos invadido e ameaçado.

Contudo, para os "abusadores de espaço" o espaço grupal é essencial, pois nele atuam e se relacionam de maneira que não conseguem fazer em outros espaços. Seus excessos e invasões são acolhidos no grupo, porque minha presença os acolhe e delimita. 
Porém, tudo o que foi apresentado e discutido aqui é apenas uma parte do vivido e observado no grupo, logo, apenas uma perspectiva do todo que é. $\mathrm{O}$ grupo é maior do que o que pode ser dito e escrito sobre ele. Sendo assim, nenhuma ideia aqui apresentada é conclusiva ou definitiva. Enquanto o grupo existir, sua "acontecência" poderá ser observada e refletida. Novos modos-deestar podem ser des-cobertos e possibilidades de encontros percebidas.

O presente artigo poderia terminar com dois pontos, como o belo livro de Clarice Lispector - "Uma aprendizagem ou o livro dos prazeres", pois tudo o que aqui foi escrito é somente o início de novas indagações.

\section{Referências bibliográficas}

Binswanger, Ludwig. (2009). O caso Jürg Zünd. São Paulo: Escuta.

Chamond, Jeanine. (2011). Fenomenologia e psicopatologia do espaço vivido segundo Ludwig Binswanger: uma introdução. Rev. abordagem gestalt. [online], 17 (1), 3-7.

Critelli, Dulce Mara. (2007). Analítica do sentido. São Paulo: Brasiliense.

Dörr, Otto. (1995). Psiquiatria Antropológica: contribuciones a uma psiquiatria de orientación fenomenológico - antropológica. Santiago: Editorial Universitaria.

Fernández, Ana María. (2006). O campo grupal: notas para uma genealogia. São Paulo: Martins Fontes.

Laing, Ronald David. (1982). O eu dividido: Estudo existencial da sanidade e da loucura. Rio de Janeiro: Editora Vozes.

Lima (2008). Prefácio. In: Messas, G. P. Psicopatologia Fenomenológica Contemporânea. São Paulo: Roca.

Lispector, Clarice. (1998). Uma aprendizagem ou o livro dos prazeres. Rio de Janeiro: Rocco.

Messas, Guilherme Peres. (2004). Psicopatologia e transformação: um esboço fenômeno-estrutural. São Paulo: Casa do Psicólogo.

(2008). As psicoses e o significado da embriaguez: uma contribuição fenômeno-estrutural. Casos Clinicos em Psiquiatria [online], 10:15 p.] www.abpbrasil.org.br/medicos/publicacoes/revista 
(2010). Ensaio sobre a Estrutura Vivida: Psicopatologia Fenomenológica Comparada. São Paulo: Roca.

Minkowski, E. (1973). El tiempo vivido. Fondo de Cultura Económica, México DF.

Pessanha, Juliano Garcia. (2009). Instabilidade Perpétua. São Paulo: Ateliê Editorial.

Santo Agostinho. (2000). Confissões. São Paulo: Nova Cultural. Tradução de J. Santos; A. Pina.

Tatossian, Arthur. (2006). A Fenomenologia das psicoses. São Paulo: Escuta.

Van Den Berg, J.H. (2000). O paciente psiquiátrico: esboço de uma psicopatologia fenomenológica. São Paulo: Editora Livro Pleno. 